\title{
miR-214 regulates papillary thyroid carcinoma cell proliferation and metastasis by targeting PSMD10
}

\author{
FANGZHOU LIU ${ }^{1 *}$, KEXIN LOU $^{2 *}$, XIAOTONG ZHAO ${ }^{3}$, JIA ZHANG $^{4}$, WEI CHEN $^{1}$, \\ YICHUN QIAN $^{1}$, YANBIN ZHAO ${ }^{1}$, YAN ZHU $^{5}$ and YUAN ZHANG ${ }^{1}$
}

\begin{abstract}
Departments of ${ }^{1} \mathrm{Head}$ and Neck Surgery and ${ }^{2}$ Pathology, Jiangsu Cancer Hospital, Jiangsu Institute of Cancer Research, The Affiliated Cancer Hospital of Nanjing Medical University, Nanjing, Jiangsu 210000; ${ }^{3}$ Department of Otorhinolaryngology and Head and Neck Surgery, Affiliated Hospital of Xuzhou Medical University, Xuzhou, Jiangsu 221000; ${ }^{4}$ PET-CT Center, Jiangsu Cancer Hospital, Jiangsu Institute of Cancer Research, The Affiliated Cancer Hospital of Nanjing Medical University;

${ }^{5}$ Department of Pathology, Jiangsu Province People's Hospital, Nanjing, Jiangsu 210000, P.R. China
\end{abstract}

Received December 1, 2017; Accepted July 25, 2018

DOI: $10.3892 / \mathrm{ijmm} .2018 .3902$

\begin{abstract}
MicroRNAs (miRNAs) have important effects on cancer occurrence and development by adjusting gene expression. The aim of the present study was to examine the role of miR-214 in papillary thyroid carcinoma cell proliferation and metastasis, and its molecular mechanisms. miR-214 was demonstrated to be markedly downregulated in papillary thyroid carcinoma tissues and cells compared with normal, and this was significantly associated with lymph node metastasis, tumor size and TNM stage. Upregulation of miR-214 significantly decreased cell proliferation, and promoted cell apoptosis and cell cycle arrest in papillary thyroid carcinoma cell lines in vitro. By contrast, downregulation of miR-214 resulted in the opposite effects. In addition, miR-214 mimics significantly decreased papillary thyroid carcinoma cell migration and invasion, which was correlated with decreased expression levels of matrix metallopeptidase (MMP)-2 and MMP-9. Restoration of miR-214 expression in papillary thyroid carcinoma cells decreased the activities associated with epithelial-mesenchymal transition (EMT). Furthermore, proteasome 26S subunit non-ATPase 10 (PSMD10) was predicted to be a target of miR-214. Experimental results demonstrated that miR-214 negatively regulated PSMD10 expression by targeting its 3 ' untranslated region directly.
\end{abstract}

Correspondence to: Professor Fangzhou Liu or Professor Yuan Zhang, Department of Head and Neck Surgery, Jiangsu Cancer Hospital, Jiangsu Institute of Cancer Research, The Affiliated Cancer Hospital of Nanjing Medical University, 42 Baiziting Road, Nanjing, Jiangsu 210000, P.R. China

E-mail: liufangzhou2017@sina.com

E-mail: zhangyuan201711@sina.com

${ }^{*}$ Contributed equally

Key words: miR-214, proteasome $26 \mathrm{~S}$ subunit non-ATPase 10 , papillary thyroid carcinoma, proliferation, migration, invasion
Knockdown of PSMD10 reduced papillary thyroid carcinoma cell clone formation, migration and invasion, most likely by repressing glycogen synthase kinase (GSK)-3 $\beta / \beta$-catenin and AKT signaling. Finally, a negative correlation was observed between the expression levels of miR-214 and PSMD10 in papillary thyroid carcinoma tissues. Taken together, these data suggested that miR-214 might be a candidate target for the treatment of papillary thyroid carcinoma.

\section{Introduction}

Papillary thyroid carcinoma (PTC), accounting for $\sim 80 \%$ of all thyroid cancers, is the most common malignant tumor of the thyroid $(1,2)$. Detected with the use of ultrasound screening, the annual incidence of PTC has increased dramatically (2). Poor prognosis is closely associated with clinical characteristics such as tumor size and lymph node metastasis (3-5). Therefore, understanding the molecular mechanisms of PTC may be helpful in the identification of novel therapeutic targets (6).

MicroRNAs (miRNAs) are small,noncoding single-chained RNAs, which comprise a series of regulators by targeting mRNAs, and causing their translation or degradation (7). Notably, a large amount of evidence indicate that miRNAs have important functions in adjusting biological behaviors, such as cell proliferation, differentiation and apoptosis $(8,9)$. Actually, miRNAs control multiple genes, which can provide new thinking for the development of human disease treatment, especially for cancer. Targeting specific miRNAs, such as miR-125a-5p and miR-337, has demonstrated promising inhibitory roles on cancer progression $(10,11)$. miR-214 is significantly downregulated in multiple types of human cancer, including hepatocellular, breast and cervical cancer (12-14), and displays the behavior of a tumor suppressor (15). However, the regulation of miR-214 and its mechanism in PTC remain unclear.

Proteasome 26S subunit non-ATPase 10 (PSMD10), also known as gankyrin, was originally cloned as an ingredient of the $26 \mathrm{~S}$ proteasome (16). It has been identified as an overexpressed protein and has complex functions in hepatocellular 
carcinoma (17). Previous studied have demonstrated that dysregulation of PSMD10 is conducive to the tumor progression, and has significant effects on tumor cell proliferation and metastasis $(18,19)$. It was reported that PSMD10 can regulate negatively numerous tumor types (20). However, the role of PSMD10 in PTC has remained unexplored.

The present study explored the role of miR-214 in PTC, and revealed that the expression of miR-214 was significantly decreased in PTC tissues and cells. Overexpression of miR-214 suppressed cell proliferation, invasion, migration and epithelial-mesenchymal transition (EMT) in the CGTH W-3 and PTC-uc3 PTC cell lines, via targeting PSMD10. Altogether, the present results demonstrated that miR-214 might be a potential target for the treatment of PTC.

\section{Materials and methods}

PTC tissue sample collection. Human clinical PTC tissues from 30 patients were collected at Jiangsu Cancer Hospital (Nanjing, China) between January 2015 and December 2016. The stage following surgery was evaluated according to the 7 th edition of American Joint Committee on Cancer Tumor Node Metastasis staging system (21). The adjacent normal tissues were isolated at the same time as matched controls. Written informed consent was obtained from all the patients and the research protocols were approved by the Ethics Committee of Jiangsu Cancer Hospital.

Cell culture. The human PTC cell lines (CGTH W-3 and PTC-uc3) and human thyroid follicular epithelial cells (Nthy-ori 3-1) were purchased from the Type Culture Collection of the Chinese Academy of Sciences (Shanghai, China). Cells were cultured in Roswell Park Memorial Institute (RPMI)-1640 medium (Invitrogen; Thermo Fisher Scientific, Inc., Waltham, MA, USA) with $10 \%$ fetal bovine serum (FBS; Gibco; Thermo Fisher Scientific, Inc.), $100 \mathrm{U} / \mathrm{ml}$ penicillin, and $100 \mu \mathrm{g} / \mathrm{ml}$ streptomycin (Sigma-Aldrich; Merck KGaA, Darmstadt, Germany), and incubated at $37^{\circ} \mathrm{C}$ in a humidified incubator with $5 \% \mathrm{CO}_{2}$.

Reverse transcription-quantitative polymerase chain reaction $(R T-q P C R)$. RNA was extracted from tissues or cells using TRIzol reagent (Thermo Fisher Scientific, Inc.) following the manufacturer's protocol. Total RNA $(2 \mu \mathrm{g})$ was reversed transcribed into cDNA using the TaqMan microRNA Reverse Transcription kit (Applied Biosystems; Thermo Fisher Scientific, Inc.). qPCR was performed in a Bio-Rad CFX96 Real-Time PCR System (Bio-Rad Laboratories, Inc., Hercules, CA, USA) using SYBR Premix Ex Taq kit (Takara Biotechnology Co., Ltd., Dalian, China) or TaqMan probes (Applied Biosystems; Thermo Fisher Scientific, Inc.), according to the manufacturer's instructions. The thermocycling conditions were as follows: $95^{\circ} \mathrm{C}$ for $5 \mathrm{~min}$ followed by 45 cycles at $95^{\circ} \mathrm{C}$ for $10 \mathrm{sec}$ and $55^{\circ} \mathrm{C}$ for $30 \mathrm{sec}$, then a melting curve analysis every $0.2^{\circ} \mathrm{C}$ from $55^{\circ} \mathrm{C}$ to $95^{\circ} \mathrm{C}$ for 2 min was obtained. Expressions were normalized to the levels of the internal reference gene GAPDH. Specific PCR primers were synthesized by Invitrogen and the sequences were as follows: miR-214 forward, 5'-TATACATCAAACAGC AGGCACA-3' and reverse, 5'-CATTCGATCTTCTCCACA
GTCTC-3'; PSMD10 forward, 5'-CGAGCTCTGGAAGGT TAAACAGCTTGGA-3' and reverse, 5'-GCTCTAGAAGAC TCACAACAGCCACAGAA-3'; GAPDH forward, 5'-AAG AAGGTGGTGAAGCAGGC-3' and reverse, 5'-TCCACCACC CTGTTGCTGTA-3'. The expression levels of miR-214 and PSMD10 were assessed using the $2^{-\Delta \Delta \mathrm{Cq}}$ method (22).

Cell transfection. miR-214 mimics (5'-ACAGCAGGCACA GACAGGCAGU-3') miR-214 inhibitors (5'-ACUGCCUGU CUGUGCCUGCUGU-3') mimics negative control (NC; 5'-UUCUCCGAACGUGUCACGUTT-3') inhibitors NC (5'-CAGUACUUUUGUGUAGUACAA-3') and PDMS10 small interfering (si) RNA (PDMS10-siRNA; 5'-CTGGCCGGG ATGAGATTGTAAAAG-3') were obtained from GenePharma Co., Ltd. (Shanghai, China). Cells were transfected at a final concentration of $50 \mathrm{nM}$ using Lipofectamine 2000 (Thermo Fisher Scientific, Inc.) for $24 \mathrm{~h}$, according to the manufacturer's protocols.

Cell proliferation assay. Cell Counting Kit-8 (CCK-8) assays were performed to evaluate cell proliferation, following the manufacturer's protocol. Briefly, transfected cells were added to 96 -well plates $\left(1 \times 10^{4}\right.$ cells/well) and then CCK-8 solution (Dojindo Molecular Technologies, Inc., Kumamoto, Japan) was added. The optical density at $450 \mathrm{~nm}$ was recorded on a microplate reader (Multiscan FC; Thermo Fisher Scientific, Inc.) at different times.

Cell apoptosis assay. Flow cytometry analysis (C6 type flow cytometer; BD Biosciences, San Jose, CA, USA) using a FACSCalibur (version 6.0; BD Biosciences) was conducted to evaluate cells apoptosis. For apoptosis analysis, cells were collected $48 \mathrm{~h}$ post-transfection and stained with fluorescein isothiocyanate (FITC)-Annexin V (5 $\mu \mathrm{l}$; Nanjing KeyGen Biotech Co., Ltd., Nanjing, China), and propidium iodide (PI; $5 \mu \mathrm{l})$.

Cell cycle analysis. Following transfection for $48 \mathrm{~h}$, cells were harvested, washed with PBS and fixed in $70 \%$ ethanol overnight at $4^{\circ} \mathrm{C}$. Then, $10 \mathrm{mg} / \mathrm{l}$ RNase $\mathrm{A}$ was added and incubated in $37^{\circ} \mathrm{C}$ for $30 \mathrm{~min}$. The cells were subsequently incubated in $10 \mathrm{~g} / \mathrm{ml} \mathrm{PI}$ at $4^{\circ} \mathrm{C}$ for $30 \mathrm{~min}$ in the dark. Cell cycle distribution was analyzed by flow cytometry. The results were analyzed using ModFit software v3.3 (BD Biosciences).

Wound-healing assay. Cells were seeded in 6-well plates and grown to $\sim 80 \%$ confluency. Cell monolayers were wounded (width, $2 \mathrm{~mm}$ ) with sterile plastic pipette tips and washed with PBS to remove cell debris. Images with a magnification of $x 40$ were captured at 0,24 and $48 \mathrm{~h}$ following wounding using a light microscope. A total of 5 fields were captured per sample and the distance of cell migration into the wound area was calculated using Image J software 1.48u (National Institutes of Health, Bethesda, MD, USA).

Cell invasion assay. Diluted matrigel (BD Biosciences) was incubated for $2 \mathrm{~h}$ at $37^{\circ} \mathrm{C}$ in the upper chamber of Transwell chambers (Corning Incorporated, Corning, NY, USA). Then, cells $\left(1 \times 10^{5} /\right.$ well $)$ were added into the upper chamber. The bottom chamber was filled with medium containing $20 \%$ FBS 
and incubated for $24 \mathrm{~h}$. Then, noninvasive cells on the upper surface were gently wiped off with cotton swabs. Invaded cells were fixed with $4 \%$ paraformaldehyde (Sigma-Aldrich; Merck $\mathrm{KGaA}$ ) and stained in $10 \%$ crystal violet (Sigma-Aldrich; Merck KGaA). Images of the invasive cells at the bottom of the chamber were captured under an inverted light microscope (TE 2000-S; Nikon Corporation, Tokyo, Japan); the quantification of the invaded cells used the mean number of cells in five fields.

Dual luciferase reporter assay. TargetScan (www.targetscan. og) (23) was used to predict the binding site of miR-214 and PSMD10 3' untranslated region (UTR) using miR-214 as a keyword on the 12th February 2017. The wild-type or mutant 3'UTR of PSMD10 (Shanghai GeneChem Co., Ltd., Shanghai, China) was cloned into pGL3 vector (Promega Corporation, Madison, WI, USA) to confirm direct target association. The wild-type contained binding sites of PSMD10 3'UTR with miR-214. Lipofectamine 2000 (Thermo Fisher Scientific, Inc.) was used for transfection for $24 \mathrm{~h}$ at $37^{\circ} \mathrm{C}$. Cells $\left(1 \times 10^{4} /\right.$ well $)$ were incubated for $48 \mathrm{~h}$. Then the luciferase activity was measured after $48 \mathrm{~h}$ using a dual-luciferase reporter assay system (Promega Corporation). Luciferase ratio was calculated for each construct. The activity was normalized to the corresponding Renilla luciferase activity.

Western blot analysis. RIPA lysis buffer was used to extract total proteins. The supernatant was collected by centrifuging at $13,282 \mathrm{x} \mathrm{g}$ at $4^{\circ} \mathrm{C}$ for $10 \mathrm{~min}$. Protein concentration was tested using the Pierce BCA Protein Assay kit (Thermo Fisher Scientific, Inc.). The samples $(30 \mu \mathrm{g})$ were separated on SDS-PAGE (10\%) and then blotted onto a polyvinylidene fluoride membrane. The membrane was blocked with $5 \%$ non-fat milk at $25^{\circ} \mathrm{C}$ for $1 \mathrm{~h}$, and then incubated with primary antibodies overnight at $4^{\circ} \mathrm{C}$, including matrix metalloproteinase (MMP)-2 (cat. no. 40994; Cell Signaling Technology Inc., Danvers, MA, USA; 1:1,000), MMP-9 (cat. no. 13667; Cell Signaling Technology; 1:1,000), E-cadherin (cat. no. 14472; Cell Signaling Technology; 1:2,000), Vimentin (cat. no. 5741; Cell Signaling Technology; 1:1,000), Fibronectin (cat. no. 4705; Cell Signaling Technology; 1:1,000), PSMD10 (cat. no. 12985; Cell Signaling Technology; 1:1,000), phosphorylated (p)-protein kinase B (AKT; cat. no. 4060; Cell Signaling Technology; 1:2,000), AKT (cat. no. 2920; Cell Signaling Technology; 1:1,000), p-glycogen synthase kinase (GSK)-3 $\beta$ (cat. no. 9323; Cell Signaling Technology; 1:1,000), GSK-3 $\beta$ (cat. no. 5676; Cell Signaling Technology; 1:1,000) and GAPDH (cat. no. 5174; Cell Signaling Technology; 1:2,000). The membrane was incubated with the corresponding horseradish peroxidase-conjugated secondary antibody (cat. no. 4410; Cell Signaling Technology; $1: 5,000)$ at $25^{\circ} \mathrm{C}$ for $2 \mathrm{~h}$. The immuno-reactivity was visualized using the ECL Western blotting kit (Beyotime Institute of Biotechnology, Beijing, China). The amount of protein was normalized to GAPDH and analyzed using ImageJ software $1.48 \mathrm{u}$ (National Institutes of Health).

Colony formation assay. PTC cells ( $1 \times 10^{4}$ cells/well) were plated in 24-well culture plates. After 12 days, cells were washed and fixed with $4 \%$ paraformaldehyde at $25^{\circ} \mathrm{C}$ for $30 \mathrm{~min}$, and then stained in $10 \%$ crystal violet. The number
Table I. Association of miR-214 expression levels and patient clinical characteristics.

\begin{tabular}{lccr}
\hline Variable & $\begin{array}{c}\text { Number } \\
\text { of patients }\end{array}$ & $\begin{array}{c}\text { Relative } \\
\text { expression }\end{array}$ & P-value \\
\hline Age (years) & & & 0.6140 \\
$\quad \leq 60$ & 15 & 0.25 & \\
$>60$ & 15 & 0.23 & \\
Sex & & & 0.2540 \\
Male & 12 & 0.21 & \\
Female & 18 & 0.25 & \\
Tumor size & & & $<0.0001$ \\
T1+T2 & 12 & 0.33 & \\
T3+T4 & 18 & 0.17 & \\
Lymphatic metastasis & & & $<0.0001$ \\
Positive & 14 & 0.16 & \\
Negative & 16 & 0.32 & \\
TNM stage & & & $<0.0001$ \\
$\quad \leq$ II & 10 & 0.34 & \\
$>$ II & 20 & 0.18 & \\
\hline
\end{tabular}

TNM, tumor, node and metastases.

of colonies containing $\geq 50$ cells was counted under a light microscope.

Statistical analysis. Data were represented as means \pm standard deviation $(n=3)$. GraphPad Prism 6 (GraphPad Software, Inc., La Jolla, CA, USA) was used to perform all the statistical analyses. When only two groups were compared, Student's t-test was conducted. One-way analysis of variance followed Bonferroni's correction as a post-hoc test was applied to compare differences between multiple groups. $\mathrm{P}<0.05$ was considered to indicate a statistically significant difference.

\section{Results}

miR-214 is downregulated in PTC tissues and cell lines. To explore the expression status of miR-214 in PTC, the expression levels of miR-214 were examined in 30 pairs of human PTC tissues and matched adjacent normal tissues by RT-qPCR. The results demonstrated that miR-214 expression was significantly downregulated in PTC tissues compared with adjacent normal tissues (Fig. 1A). In addition, the correlation of miR-214 expression to various clinical features, including age, gender, tumor size, lymph node metastasis and TNM stage, was investigated in PTC. The results revealed that decreased expression of miR-214 was associated with lymph node metastasis, tumor size and advanced TNM stage (Table I).

Next, the expression levels of miR-214 were determined in one human thyroid follicular epithelial cell line (Nthy-ori 3-1) and two PTC cell lines (CGTH W-3 and PTC-uc3). The results demonstrated that miR-214 was markedly downregulated in the PTC cell lines (CGTH W-3 and PTC-uc3) compared 
A

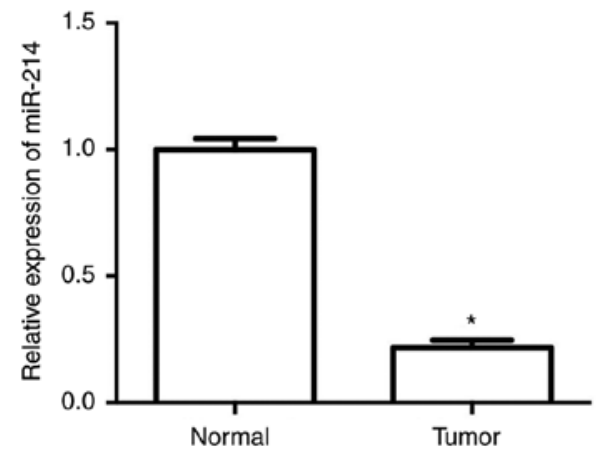

B

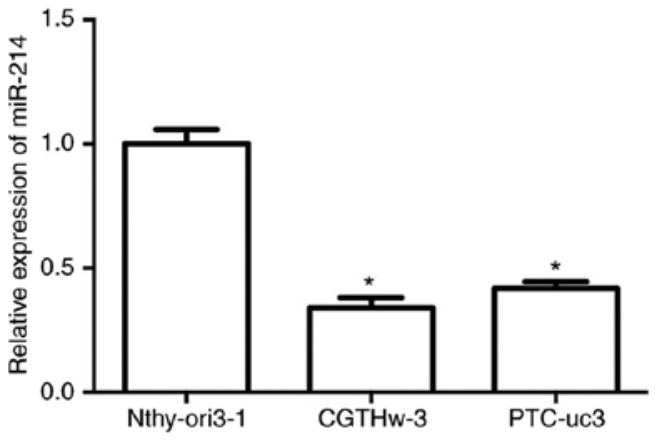

Figure 1. miR-214 is significantly downregulated in PTC tissues and cell lines. (A) Expression levels of miR-214 in 30 pairs of human PTC tissues and adjacent normal tissues. "P<0.05 compared with normal. (B) Expression levels of miR-214 in the PTC cell lines CGTH W-3 and PTC-uc3, and in the normal thyroid follicular epithelial cell line Nthy-ori3-1. ${ }^{*}<<0.05$ compared with Nthy-ori3-1. PTC, papillary thyroid carcinoma.

with the normal Nthy-ori 3-1 cell line (Fig. 1B). These data indicated that the expression of miR-214 was decreased in both PTC tissues and cells, suggesting that miR-214 may be important in PTC development and metastasis.

miR-214 overexpression suppresses cell proliferation, and induces cell apoptosis and cell cycle arrest in PTC cells. CGTH W-3 and PTC-uc3 cells were transfected with miR-214 mimics or miR-214 inhibitors or corresponding negative control (NC) to evaluate the effect of miR-214 in PTC. The results indicated that miR-214 mimics increased expression of miR-214 compared with the mimics NC group in CGTH W-3 and PTC-uc3 cells, while its expression was significantly decreased in the miR-214 inhibitors-transfected group compared with the inhibitors NC group (Fig. 2A).

CCK-8 assay results demonstrated that transfection with miR-214 mimics significantly decreased the proliferation of CGTH W-3 and PTC-uc3 cells compared with the mimics NC group (Fig. 2B). By contrast, transfection of miR-214 inhibitors resulted in the opposite effect (Fig. 2B). Flow cytometry analysis demonstrated that miR-214 mimics clearly promoted cell apoptosis compared with the mimics NC group, while miR-214 inhibitors markedly decreased apoptosis compared with the inhibitors $\mathrm{NC}$ group (Fig. 2C). In addition, cell cycle phase distribution analysis revealed that miR-214 mimics significantly increased the $\%$ of cells in the $\mathrm{G}_{0} / \mathrm{G}_{1}$ phases of the cell cycle in CGTH W-3 and PTC-uc3 cells compared with the mimics NC group (Fig. 2D). By contrast, inhibition of miR-214 decreased the $\%$ of cells in the $\mathrm{G}_{0} / \mathrm{G}_{1}$ phases in both CGTH W-3 and PTC-uc3 cells compared with the inhibitors NC group (Fig. 2D), suggesting that miR-214 affects PTC cell cycle regulation.

miR-214 decreases PTC cell migration and invasion and inhibits EMT. The effects of miR-214 on PTC cell migration and invasion were evaluated next. The results demonstrated that miR-214 mimics decreased cell migration in CGTH W-3 and PTC-uc3 cells, while depletion of miR-214 resulted in a significant increase in cell migration, compared with the respective NC group (Fig. 3A). Similarly, miR-214 mimics significantly decreased CGTH W-3 and PTC-uc3 cell invasion, while inhibition of miR-214 decreased cell invasion, compared with the respective $\mathrm{NC}$ group (Fig. 3B).
Furthermore, the expression of proteins associated with tumor cell metastasis was examined in CGTH W-3 and PTC-uc3 cells by western blotting. The results demonstrated that miR-214 mimics significantly decreased the expression levels of matrix metallopeptidase (MMP)-2 and MMP-9 (Fig. 4A). However, inhibition of miR-214 promoted the upregulation of MMP-2 and MMP-9 in both CGTH W-3 and PTC-uc3 cells (Fig. 4A). In addition, the results revealed that overexpression of miR-214 reversed EMT-associated protein expression in CGTH W-3 and PTC-uc3 cells; miR-214 mimics increased the expression of E-cadherin and inhibited the expression of $\mathrm{N}$-cadherin and vimentin compared with the mimics NC group (Fig. 4B). However, the EMT-associated expression displayed opposite patterns in the miR-214 inhibitor-transfected groups (Fig. 4B).

PSMD10 is a direct target of $m i R-214$. The TargetScan software was utilized to analyze potential gene targets for miR-214 (23), and PSMD10 was predicted to be a target gene of miR-214 (Fig. 5A). Dual luciferase reporter assays were then employed to test the hypothesis that miR-214 directly targets PSMD10. The results indicated that miR-214 mimics reduced the luciferase activity of a PSMD10-3'-UTR wild-type reporter plasmid (Fig. 5B), while the luciferase activity of a PSMD10-3'-UTR mutant reporter was not affected. In addition, miR-214 mimics downregulated the expression of PSMD10 in CGTH W-3 and PTC-uc3 cells at the mRNA and protein levels, while miR-214 inhibitors markedly increased the expression of PSMD10 compared with the inhibitors NC group (Fig. 5C and D). These results demonstrated that PSMD10 was a direct target of miR-214.

PSMD10 knockdown reduces the proliferation, migration and invasion potential of PTC cells. First, RT-qPCR was used to verify that PSMD10 levels were successfully silenced by siRNA transfection compared with control, in both CGTH W-3 and PTC-uc3 cells (Fig. 6A). Then, the effects of PSMD10 silencing were evaluated in the PTC cells. Proliferation capacity was determined by colony formation assay. The results demonstrated that colony formation in the PSMD10-siRNA transfection group was markedly decreased compared with the control group, in both CGTH 

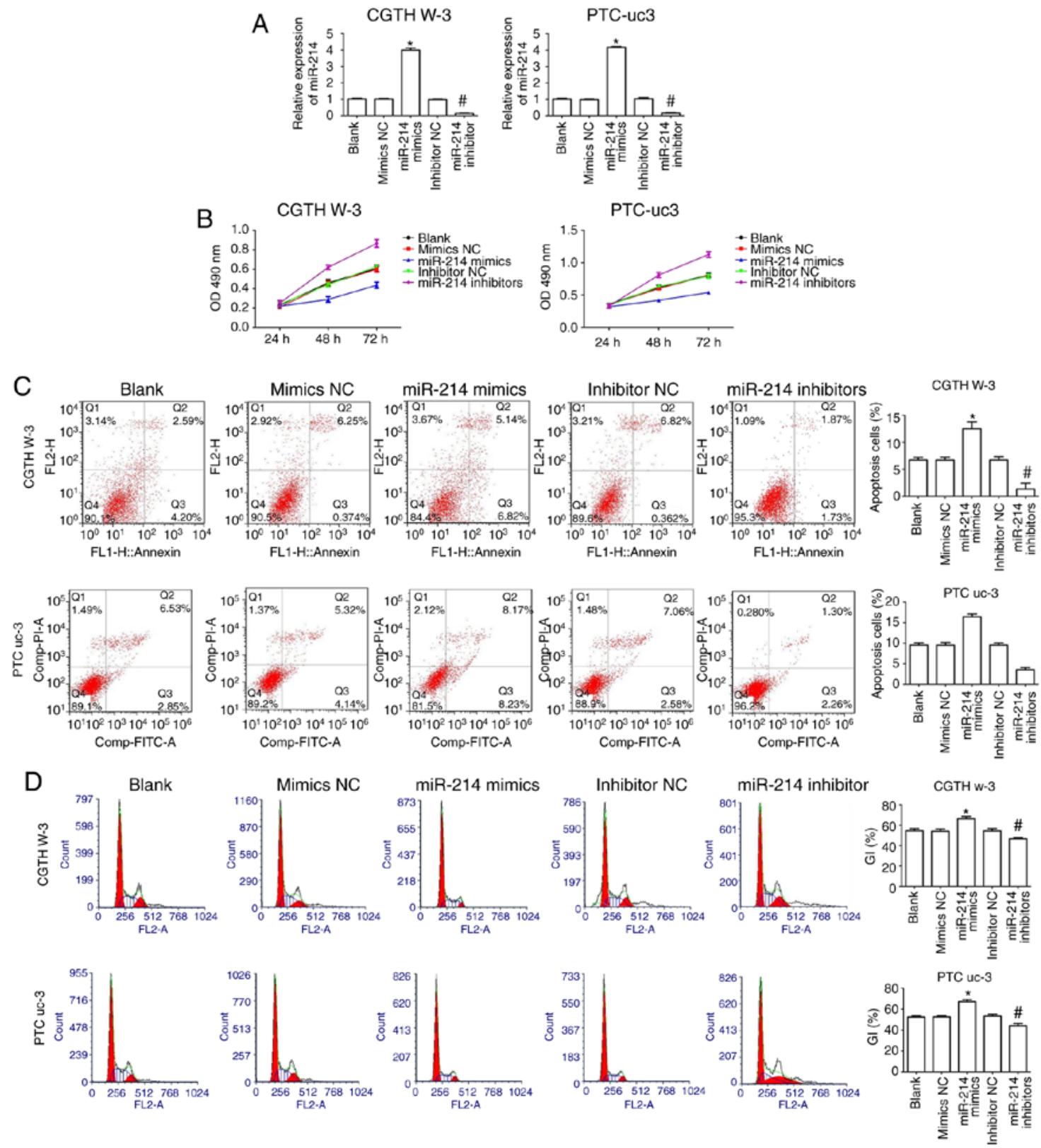

Figure 2. Overexpression of miR-214 suppresses proliferation and induces apoptosis and cell cycle arrest in PTC cells. (A) Transfection efficiency of miR-214 mimics and inhibitors was evaluated by reverse transcription-quantitative polymerase chain reaction. (B) CCK-8 assay was performed to evaluate cell proliferation. (C) Flow cytometry was used to evaluate cell apoptosis. (D) Flow cytometry was used to examine cell cycle phase distribution. ${ }^{*} \mathrm{P}<0.05$ compared with mimics NC; "P<0.05 compared with inhibitor NC. PTC, papillary thyroid carcinoma; NC, negative control; OD, optical density.

W-3 and PTC-uc3 cells (Fig. 6B). In addition, cell migration was significantly decreased in CGTH W-3 and PTC-uc3 cells transfected with PSMD10-siRNA (Fig. 6C). Finally, the cell invasion rate was significantly decreased in CGTH W-3 and PTC-uc3 cells in the PSMD10-siRNA group compared with the control group (Fig. 6D).

miR-214 expression is inversely correlated with PSMD10 expression in PTC tissues. To further investigate the molecular basis of PSMD10-mediated antitumor effects, the role of PSMD10 was examined in regulating glycogen synthase kinase (GSK)-3 $\beta / \beta$-catenin signaling in CGTH W-3 and PTC-uc3 cells. The results demonstrated that PSMD10 downregulation significantly inhibited phosphorylation of GSK-3 $\beta$ and $\beta$-catenin (Fig. 7A). Furthermore, the activity of AKT was markedly clearly decreased in the PSMD10-siRNA group. These data indicated that PSMD10 repressed GSK- $3 \beta / \beta$-catenin and AKT signaling in PTC cells.

Next, the correlation between the expression levels of miR-214 and PSMD10 was evaluated in PTC tissues. The results revealed that the expression of miR-214 was inversely correlated with the expression of PSMD10 in PTC tissues (Fig. 7B).

\section{Discussion}

PTC represents one of the most common thyroid malignancies, which is characterized by frequent recurrence and high mortality due to fast growth and metastasis. The present study 

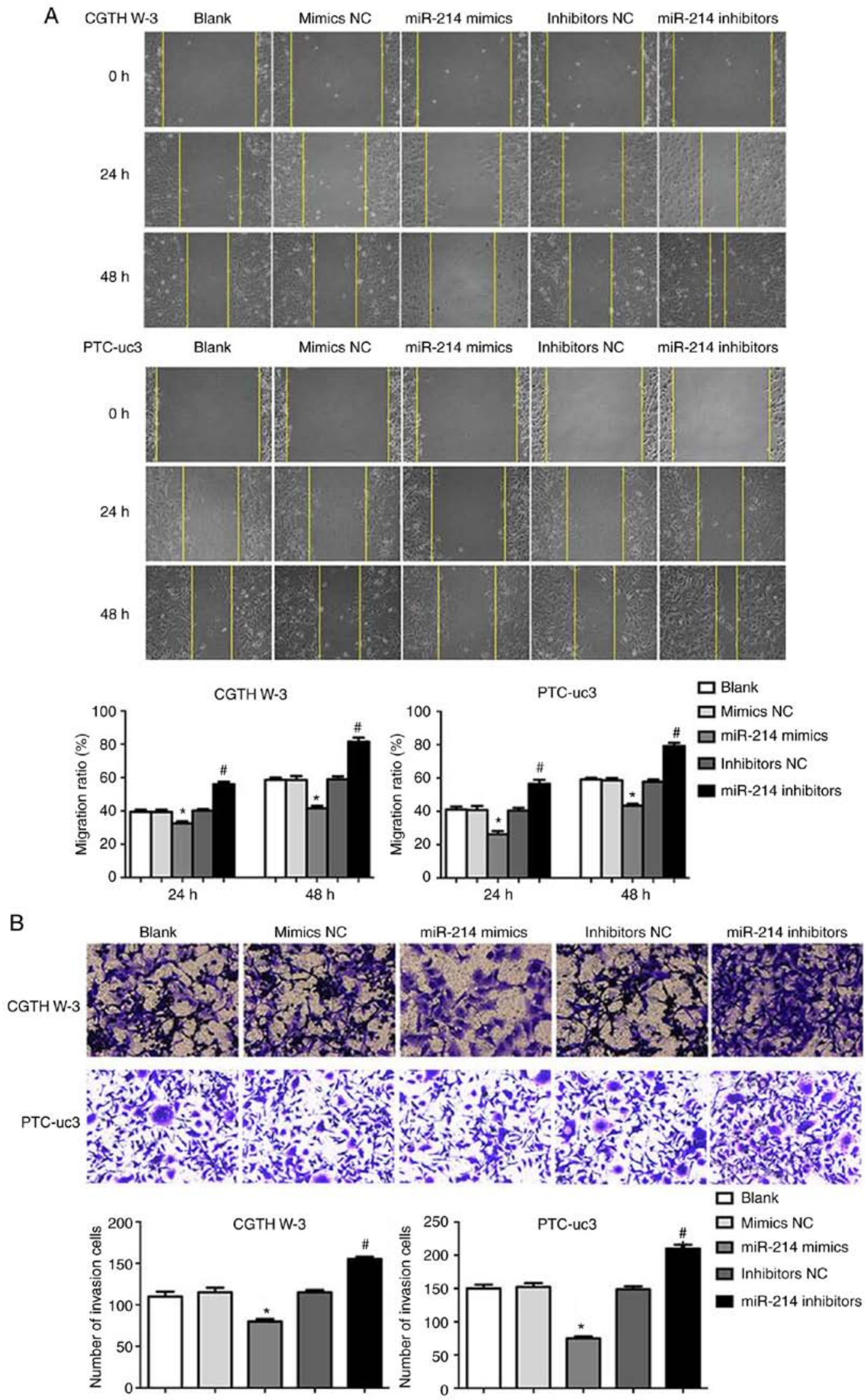

Figure 3. Overexpression of miR-214 suppresses PTC cell migration and invasion. (A) Wound-healing assays were performed to detect PTC cell migration. (B) Transwell invasion assays were performed to evaluate cell invasion. "P $<0.05$ compared with mimics NC; ${ }^{*} \mathrm{P}<0.05$ compared with inhibitor NC. PTC, papillary thyroid carcinoma; $\mathrm{NC}$, negative control.

focused on the role of miRNA in regulating the growth and metastasis of PTC.
Evidence has indicated that the expression of miR-214 is significantly decreased in various types of cancer, including 

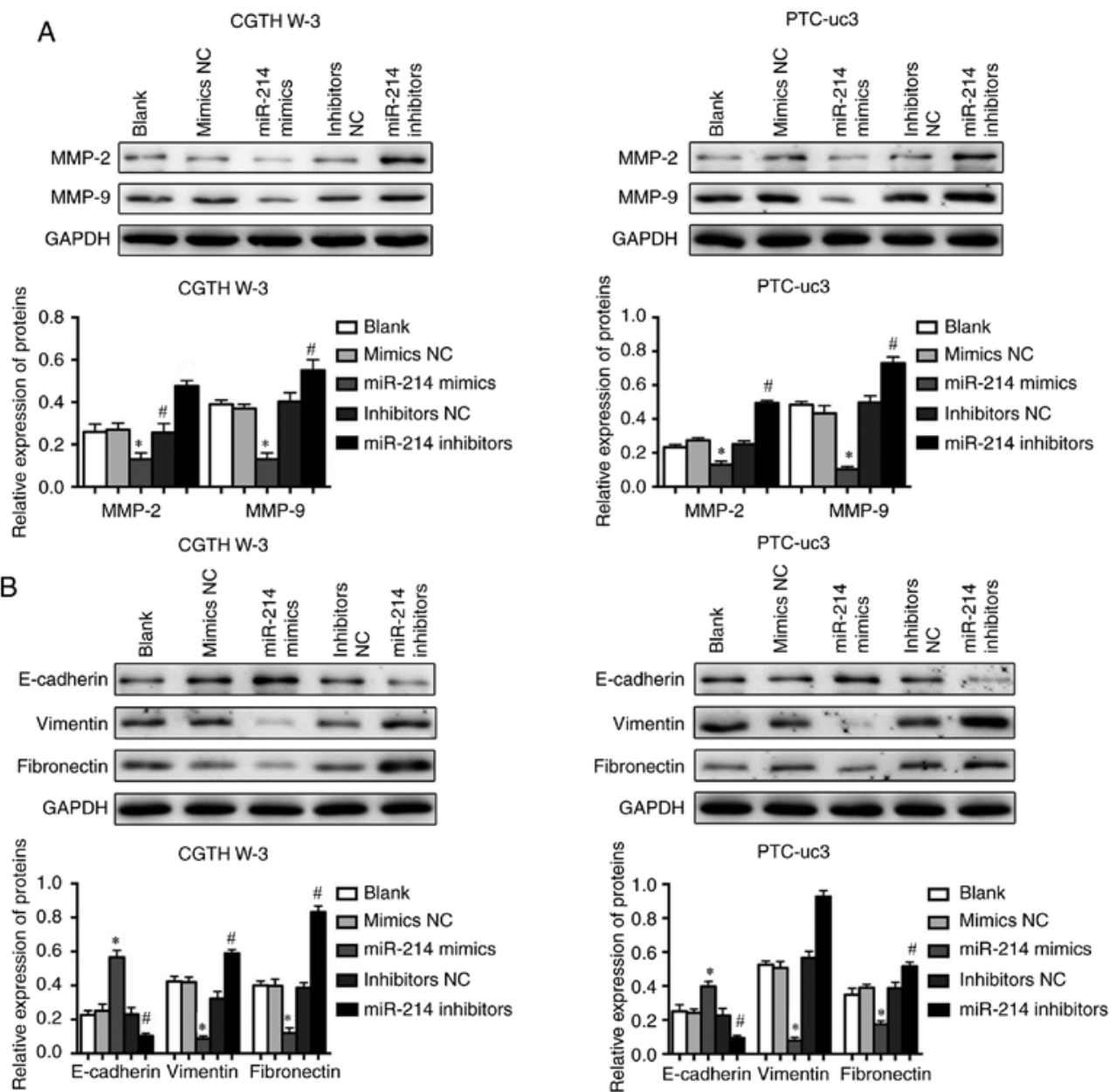

Figure 4. Overexpression of miR-214 downregulates MMPs and inhibits EMT. Expression levels of (A) MMP-2 and MMP-9, and (B) EMT-related proteins E-cadherin, vimentin and $\mathrm{N}$-cadherin, were evaluated by western blotting. ${ }^{*} \mathrm{P}<0.05$ compared with mimics $\mathrm{NC}$; ${ }^{\text {} \mathrm{P}<0.05}$ compared with inhibitor NC. MMP, matrix metallopeptidase; EMT, epithelial-mesenchymal transition; NC, negative control.
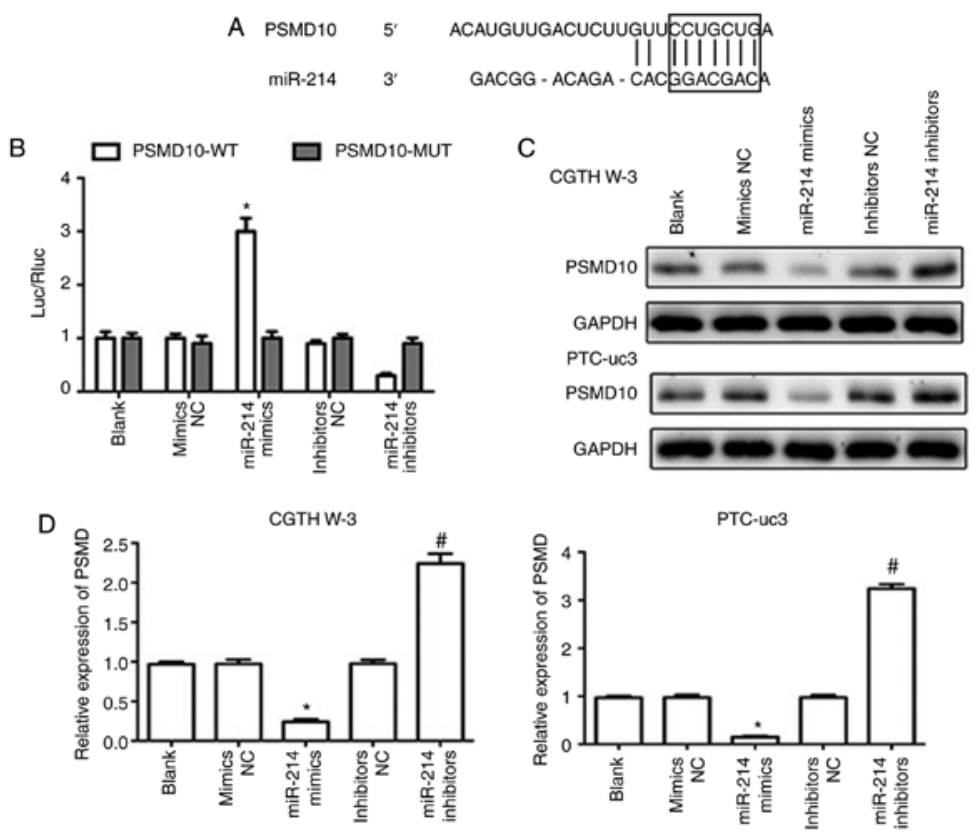

Figure 5. PSMD10 is a direct target of miR-214. (A) TargetScan analysis was performed to predict the binding between miR-214 and PSMD10. (B) Luciferase reporter assays were used to confirm the direct binding of miR-214 in the 3'-UTR of PSMD10. (C) Protein expression levels of PSMD10 were detected by western blotting. (D) mRNA expression levels of PSMD10 were detected by reverse transcription-quantitative polymerase chain reaction. ${ }^{*} \mathrm{P}<0.05$ compared with mimics NC; ${ }^{~} \mathrm{P}<0.05$ compared with inhibitor NC. PSMD10, proteasome $26 \mathrm{~S}$ subunit non-ATPase 10; UTR, untranslated region; WT, wild-type; MUT, mutant; NC, negative control. 

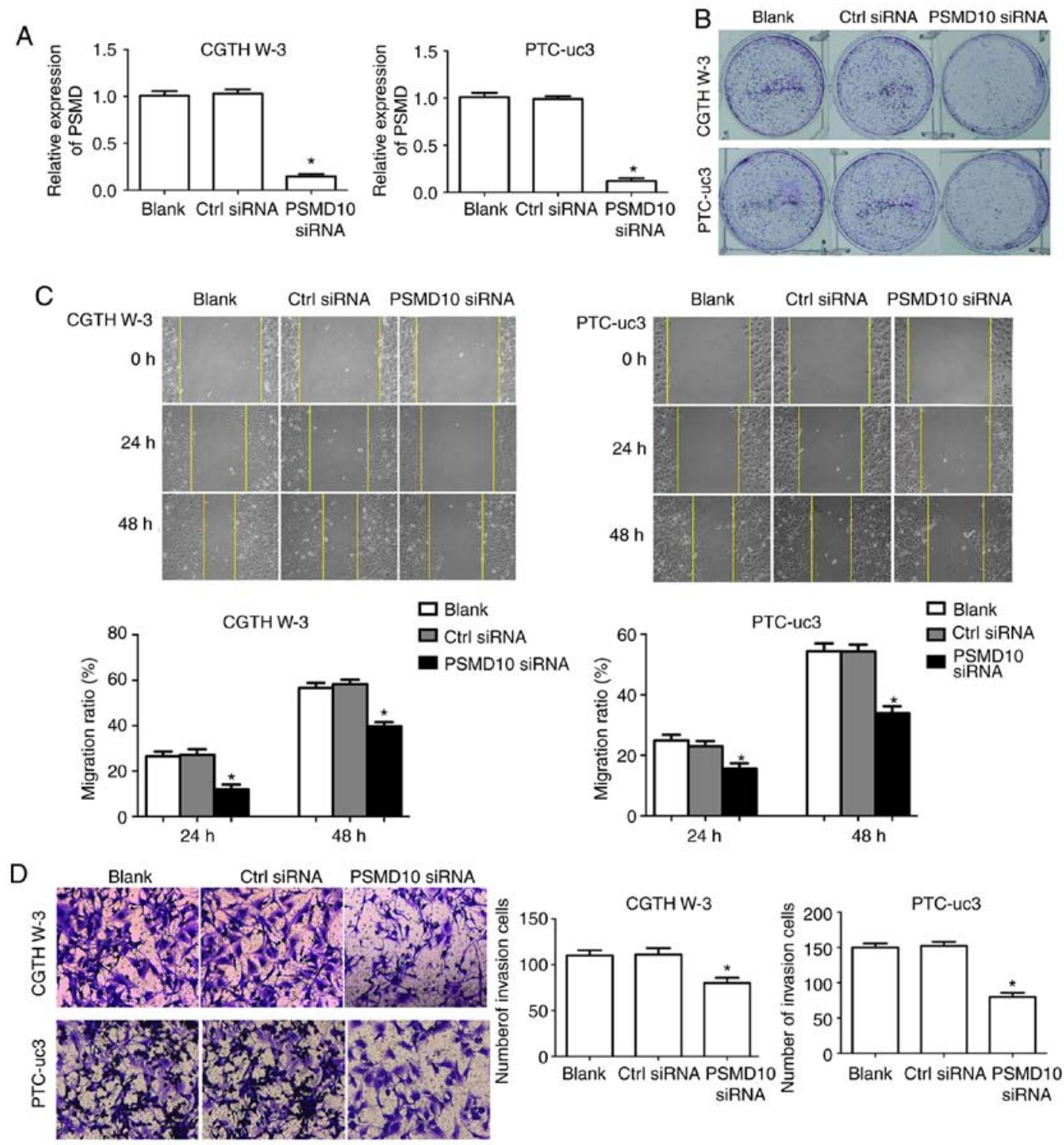

Figure 6. PSMD10 knockdown inhibits PTC cell colony formation, migration and invasion. (A) Transfection efficiency of the PSMD10 siRNA was evaluated by reverse transcription-quantitative polymerase chain reaction. (B) Colony formation assays revealed that PSMD10 siRNA decreased PTC cell colony formation. (C) Wound healing assays revealed that PSMD10 siRNA decreased PTC cell migration. (D) Transwell assays revealed that PSMD10 siRNA decreased cell invasion. ${ }^{*} \mathrm{P}<0.05$ compared with control siRNA. PSMD10, proteasome $26 \mathrm{~S}$ subunit non-ATPase 10; PTC, papillary thyroid carcinoma; si, small interfering; Ctrl, control.

hepatocellular (24), ovarian (25), cervical (26) and prostate cancer (27). In the present study, miR-214 was also identified as a downregulated miRNA in PTC. This is the first study to demonstrate that miR-214 is dysregulated in PTC. In addition, the dysregulated expression of miR-214 has also been associated with invasion, metastasis and TNM stage in the gastric cancer tissues (28). In the present study, downregulation of miR-214 was associated with lymph node metastasis, tumor size and TNM stage.

The dysregulated expression of miR-214 in cancer caused researchers to explore the effects of its tumor specificity (16). miR-214 inhibits cell proliferation in breast cancer and hepatic carcinomas $(29,30)$. Furthermore, miR-214 inhibits DNA replication and apoptosis by upregulating the expression of p53, p21 and BCL2 associated X (Bax) (31). Similarly, the present study demonstrated that overexpression of miR-214 inhibited PTC cell proliferation, induced PTC cell apoptosis and arrested PTC cell cycle. miR-214 has been reported to significantly suppress hepatocellular carcinoma cell invasion by downregulating $\beta$-catenin and enhancer of zeste 2 polycomb repressive complex 2 subunit (Ezh2) (24). In addition, $\beta$-catenin leads to malignancy in breast and hepatic cancer by regulating the expression of its downstream genes, cyclin D1 and E-cadherin (24). Notably, miR-214 inhibits the expression of Ezh2 and decreases esophageal squamous carcinoma cell migration and invasion (32), which indicates that miR-214 has a key role in regulating cancer invasion and metastasis. The present study suggested that upregulation of miR-214 could inhibit PTC cell migration, invasion and EMT in PTC cells.

Identifying the targets of miRNAs may help elucidate the pathogenesis of cancer (26). It has been reported that miR-214 has several validated gene targets, including transcription factor AP-2 $\alpha$ (TFAP2), phosphatase and tensin homolog (PTEN), EZH2 and fibroblast growth factor receptor 1 


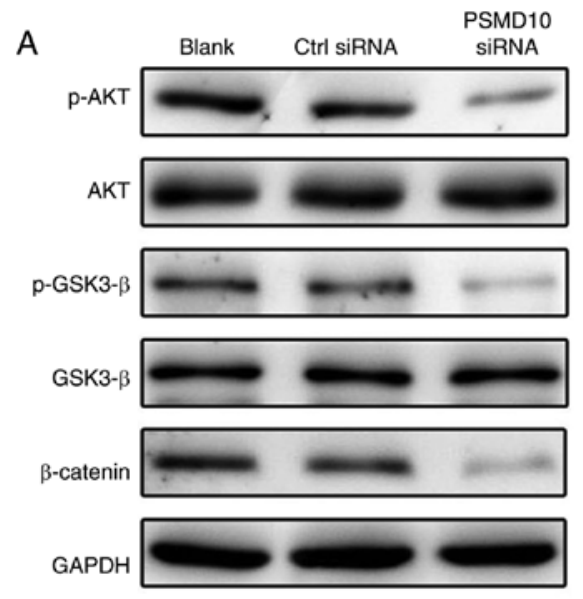

CGTH W-3

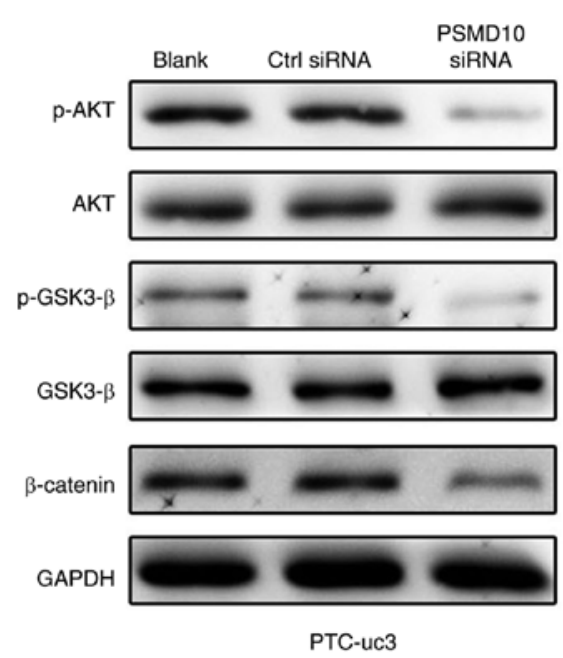

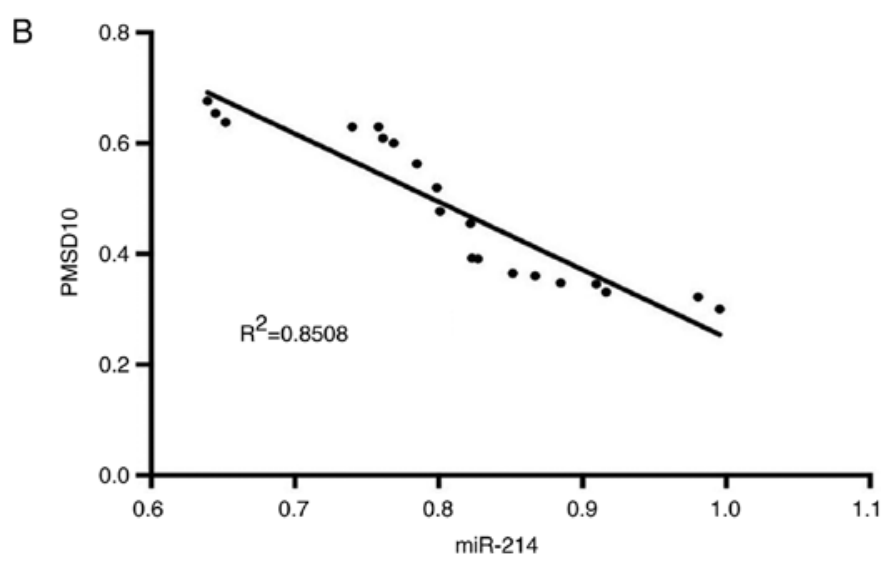

Figure 7. miR-214 expression is inversely correlated with PSMD10 expression in PTC tissues. (A) The phosphorylation activities of AKT and GSK-3 $\beta$, and the protein expression levels of $\beta$-catenin, were examined in PTC cells by western blotting. PSMD10 knockdown repressed GSK-3 $\beta / \beta$-catenin and AKT signaling in PTC cells. (B) Correlation analysis of the miR-214 expression levels and the PSMD10 expression levels in 30 pairs of human PTC tissues. PSMD10, proteasome 26S subunit non-ATPase 10; PTC, papillary thyroid carcinoma; GSK, glycogen synthase kinase; si, small interfering; Ctrl, control; p-, phosphorylated.

(FGFR1) (33-35). In the present study, upregulation of miR-214 decreased the expression levels of PSMD10 in PTC cells. Furthermore, the present study demonstrated that inhibition of PSMD10 decreased PTC cell proliferation, migration and invasion. PSMD10 is a regulator of colorectal cancer by phosphoinositide 3-kinase (PI3K)/GSK-3 $\beta / \beta$-catenin pathway activation (36). The present study demonstrated that PSMD10 downregulation repressed GSK-3 $\beta / \beta$-catenin and AKT signaling in PTC cells.

In conclusion, the present study is the first report that miR-214 functions as a tumor suppressor in PTC cells by targeting PSMD10, suggesting that it may be a potential target for the treatment of PTC.

\section{Acknowledgements}

Not applicable.

\section{Funding}

This work was supported by the Key Projects of Nanjing Science and Technology Commission (grant no. 201402006) and the Key Projects of Jiangsu Provincial Science and Technology Department (grant no. BE2016796).

\section{Availability of data and materials}

The analyzed datasets generated during the study are available from the corresponding author on reasonable request.

\section{Authors' contributions}

FL and YZhang conceived and designed the experiments. FL, KL, XZ and JZ performed the experiments. WC, YQ and YZhao analyzed the data. FL, YZhu and YZhang wrote the paper. All authors read and approved the final manuscript.

\section{Ethics approval and consent to participate}

Written informed consent was obtained from all the patients and the research protocols were approved by the Ethics Committee of Jiangsu Cancer Hospital.

\section{Patient consent for publication}

Informed consent was obtained from the subjects for participation in this study. 


\section{Competing interests}

The authors declare that they have no competing interests.

\section{References}

1. Chen AY, Jemal A and Ward EM: Increasing incidence of differentiated thyroid cancer in the United States, 1988-2005. Cancer 115: 3801-3807, 2009.

2. Davies L and Welch HG: Increasing incidence of thyroid cancer in the United States, 1973-2002. JAMA 295: 2164-2167, 2006

3. Voutilainen PE, Multanen MM, Leppäniemi AK, Haglund CH, Haapiainen RK and Franssila KO: Prognosis after lymph node recurrence in papillary thyroid carcinoma depends on age Thyroid 11: 953-957, 2001.

4. Chou CK, Chen RF, Chou FF, Chang HW, Chen YJ, Lee YF, Yang KD, Cheng JT, Huang CC and Liu RT: miR-146b is highly expressed in adult papillary thyroid carcinomas with high risk features including extrathyroidal invasion and the BRAF(V600E) mutation. Thyroid 20: 489-494, 2010.

5. Brown RL, de Souza JA and Cohen EE: Thyroid cancer: Burden of illness and management of disease. J Cancer 2: 193-199, 2011.

6. Chou CK, Yang KD, Chou FF, Huang CC, Lan YW, Lee YF, Kang HY and Liu RT: Prognostic implications of miR-146b expression and its functional role in papillary thyroid carcinoma J Clin Endocrinol Metab 98: E196-E205, 2013.

7. Jazdzewski K, Liyanarachchi S, Swierniak M, Pachucki J, Ringel MD, Jarzab B and de la Chapelle A: Polymorphic mature microRNAs from passenger strand of pre-miR-146a contribute to thyroid cancer. Proc Natl Acad Sci USA 106: 1502-1505, 2009.

8. Li M, Teruya-Feldstein $\mathrm{J}$ and Weinberg RA: Tumour invasion and metastasis initiated by microRNA-10b in breast cancer. Nature 449: 682-688, 2007.

9. Vriens MR, Weng JL, Suh I, Huynh N, Guerrero MA, Shen WT, Duh QY, Clark OH and Kebebew E: MicroRNA expression profiling is a potential diagnostic tool for thyroid cancer Cancer 118: 3426-3432, 2012.

10. Zhong L, Sun S, Shi J, Cao F, Han X and Chen Z: MicroRNA-125a-5p plays a role as a tumor suppressor in lung carcinoma cells by directly targeting STAT3. Tumor Biol 39: $1010428317697579,2017$.

11. Dong W, Li B, Wang J, Song Y, Zhang Z and Fu C: MicroRNA-337 inhibits cell proliferation and invasion of cervical cancer through directly targeting specificity protein 1 . Tumor Biol 39: $1010428317711323,2017$.

12. Wang P, Chen S, Fang H, Wu X, Chen D, Peng L, Gao Z and Xie C: miR-214/199a/199a* cluster levels predict poor survival in hepatocellular carcinoma through interference with cell-cycle regulators. Oncotarget 7: 929-945, 2016.

13. Zhang J, Su B, Gong C, Xi Q and Chao T: miR-214 promotes apoptosis and sensitizes breast cancer cells to doxorubicin by targeting the RFWD2-p53 cascade. Biochem Bioph Res Co 478: 337-342, 2016

14. Peng R, Men J, Ma R, Wang Q, Wang Y, Sun Y and Ren J: miR-214 down-regulates ARL2 and suppresses growth and invasion of cervical cancer cells. Biochem Bioph Res Co 484: 623-630, 2017.

15. Penna E, Orso F and Taverna D: miR-214 as a key hub that controls cancer networks: Small player, multiple functions. J Invest Dermatol 135: 960-969, 2015.

16. Hori T, Kato S, Saeki M, DeMartino GN, Slaughter CA, Takeuchi J, Toh-e A and Tanaka K: cDNA cloning and functional analysis of p28 (Nas6p) and p40.5 (Nas7p), two novel regulatory subunits of the 26S proteasome. Gene 216: 113-122, 1998.

17. Higashitsuji H, Itoh K, Nagao T, Dawson S, Nonoguchi $K$, Kido T, Mayer RJ, Arii S and Fujita J: Reduced stability of retinoblastoma protein by gankyrin, an oncogenic ankyrin-repeat protein overexpressed in hepatomas. Nat Med 6: 96-99, 2000.

18. Zhen C, Chen L, Zhao Q, Liang B, Gu YX, Bai ZF, Wang K, $\mathrm{Xu} X$, Han QY, Fang DF, et al: Gankyrin promotes breast cancer cell metastasis by regulating Rac1 activity. Oncogene 32: 3452-3460, 2000.

19. Meng Y, He L, Guo X, Tang S, Zhao X, Du R, Jin J, Bi Q, Li H, Nie Y, et al: Gankyrin promotes the proliferation of human pancreatic cancer. Cancer Lett 297: 9-17, 2010.
20. Uddin MH, Choi MH, Kim WH, Jang JJ and Hong ST: Involvement of PSMD10, CDK4, and tumor suppressors in development of intrahepatic cholangiocarcinoma of syrian golden hamsters induced by clonorchis sinensis and N-Nitrosodimethylamine. PLoS Negl Trop Dis 9: e0004008, 2015.

21. Edge SB, Byrd DR, Compton CC, Fritz AG and Greene FL: AJCC cancer staging manual. 7th edition. Springer, New York, NY, 2010.

22. Livak KJ and Schmittgen TD: Analysis of relative gene expression data using real-time quantitative PCR and the 2(-delta delta C(T)) methods. Methods 25: 420-408, 2001

23. Agarwal V, Bell GW, Nam J and Bartel DP: Predicting effective microRNA target sites in mammalian mRNAs. Elife 4: e05005, 2015.

24. Xia H, Ooi LL and Hui KM: MiR-214 targets $\beta$-catenin pathway to suppress invasion, stem-like traits and recurrence of human hepatocellular harcinoma. PLoS One 7: e44206, 2012.

25. Mitra AK, Zillhardt M, Hua Y, Tiwari P, Murmann AE, Peter ME and Lengyel E: MicroRNAs reprogram normal fibroblasts into cancer-associated fibroblasts in ovarian cancer. Cancer Discov 2: 1100-1108, 2012

26. Wang F, Liu M, Li X and Tang H: MiR-214 reduces cell survival and enhances cisplatin-induced cytotoxicity via down-regulation of Bcl212 in cervical cancer cells. FEBS Lett 587: 488-495, 2013.

27. Srivastava A, Goldberger H, Dimtchev A, Ramalinga M, Chijioke J, Marian C, Oermann EK, Uhm S, Kim JS, Chen LN, et al: MicroRNA profiling in prostate cancer-the diagnostic potential of urinary miR-205 and miR-214. PLoS One 8: e76994, 2013

28. Yang TS, Yang XH, Wang XD, Wang YL, Zhou B and Song ZS: MiR-214 regulate gastric cancer cell proliferation, migration and invasion by targeting PTEN. Cancer Cell Int 13: 68, 2013.

29. Derfoul A, Juan AH, Difilippantonio MJ, Palanisamy N, Ried T and Sartorelli V: Decreased microRNA-214 levels in breast cancer cells coincides with increased cell proliferation, invasion and accumulation of the Polycomb Ezh2 methyltransferase. Carcinogenesis 32: 1607-1614, 2011.

30. Duan Q, Wang X, Gong W, Ni L, Chen C, He X, Chen F, Yang L, Wang P and Wang DW: ER stress negatively modulates the expression of the miR-199a/214 cluster to regulates tumor survival and progression in human hepatocellular cancer. PLoS One 7: e31518, 2012.

31. Misiewicz-Krzeminska I, Sarasquete ME, Quwaider D, Krzeminski P, Ticona FV, Paino T, Delgado M, Aires A, Ocio EM, Garcia-Sanz R, et al: Restoration of microRNA-214 expression reduces growth of myeloma cells through positive regulation of P53 and inhibition of DNA replication. Haematologica 98: 640-648, 2013.

32. Huang SD, Yuan Y, Zhuang CW, Li BL, Gong DJ, Wang SG, Zeng ZY and Cheng HZ: MicroRNA-98 and microRNA-214 post-transcriptionally regulate enhancer of zeste homolog 2 and inhibit migration and invasion in human esophageal squamous cell carcinoma. Mol Cancer 11: 51, 2012.

33. Penna E, Orso F, Cimino D, Tenaglia E, Lembo A, Quaglino E, Poliseno L, Haimovic A, Osella-Abate S, De Pittà C, et al: microRNA-214 contributes to melanoma tumour progression through suppression of TFAP2C. EMBO J 30: 1990-2007, 2011.

34. Volinia S, Calin GA, Liu CG, Ambs S, Cimmino A, Petrocca F, Visone R, Iorio M, Roldo C, Ferracin M, et al: A microRNA expression signature of human solid tumors defines cancer gene targets. Proc Natl Acad Sci USA 103: 2257-2261, 2006.

35. Chen DL, Wang ZQ, Zeng ZL, Wu WJ, Zhang DS, Luo HY, Wang F, Qiu MZ, Wang DS, Ren C, et al: Identification of microRNA-214 as a negative regulator of colorectal cancer liver metastasis via regulation of fibroglast growth factor 1 expression. Hepatology 60: 598-609, 2014.

36. He F, Chen H, Yang P, Wu Q, Zhang T, Wang C, Wei J, Chen Z, $\mathrm{Hu} \mathrm{H}, \mathrm{Li} \mathrm{W}$ and Cao J: Gankyrin sustains PI3K/GSK-3 $\beta / \beta$-catenin signal activation and promotes colorectal cancer aggressiveness and progression. Oncotarget 7: 81156-81171, 2016.

This work is licensed under a Creative Commons Attribution-NonCommercial-NoDerivatives 4.0 International (CC BY-NC-ND 4.0) License. 